\title{
Going Public with Pedagogical Inquiries: SoTL as a Methodology for Faculty Professional Development
}

\begin{abstract}
In this paper, I discuss SoTL as a methodology for the professional development of academics. I propose that as an agentic form of inquiry that focuses on processes, boundary-crossing, and making public its findings, SoTL is a sophisticated methodology that brings the activities of teaching and research in close alignment, and contributes to developing an approach to inquiry that differs from what I have called "managed" research. I propose that, as a methodology for professional development, SoTL provides a space for dialogic critique of singular investigations into practice that contribute to advancing individual and collective knowledge of the field of higher education. I argue that in a context where approaches to practice have become driven by competitivity and international rankings that rely on objectivist understandings of practice for their judgments, SoTL presents an alternative, rich model of practice.
\end{abstract}

\section{KEYWORDS}

SoTL, faculty development, democratic, dialogic

The term Scholarship of Teaching and Learning (SoTL) appears endowed with multiple meanings. Commentators on SoTL have examined this notion from an array of perspectives, and there are many interpretations of what it is. It is a notion that appears draped in mystery but for the happy few that are engaged with its practice. SoTL has been criticised for its lack of criticality and the elusiveness of its transformative potential (Kreber, 2013). Some ambiguity has been detected as to its relation to other forms of scholarships (Cousin, 2008) and in respect of the activities it actually entails (Brew, 2007). A number of interrogations on SoTL concern its status in and contribution to the field of higher education research (Cousin, 2008; Brew, 2011; Fanghanel, 2012). Is it a minor form of research? Is it an exemplary form of inquiry (because of its interdisciplinary, open processes)? An established view of SoTL is that it is a form of inquiry in student learning that informs and enhances teaching practice, and therefore improves student learning (Prosser \& Trigwell, 2009). A great puzzle is that SoTL is a form of inquiry deeply anchored in the discipline and at the same time vibrantly interdisciplinary (Hutchings \& Shulman, 1999; Huber \& Morreale, 2002; Parker, 2002). Hutchings, Huber and Ciccone (2011) have emphasised this hybrid character and the openness and intellectual dimen- 
sion of SoTL. Perhaps one of the greatest debates within the SoTL community over the past decade relates to its theoretical capability (Hutchings, 2007; Hutchings \& Huber, 2008). Both within and outside the US, SoTL remains a relatively obscure concept that has, however, gained momentum worldwide (McNay, 2009). It has become more prominent in the UK over the past decade, being associated with state-funded initiatives aimed at enhancing teaching and learning across the higher education sector (Fanghanel, 2008).

In this paper, rather than adding to those definitional quandaries, I choose to reflect on what SoTL can do rather than on what SoTL can mean. I propose that as an agentic form of inquiry that focuses on processes, boundary-crossing, and making public its findings, SoTL is a sophisticated methodology for professional development. It brings the activities of teaching and research in closer alignment and contributes to developing an approach to inquiry that differs from what I have called "managed" research (Fanghanel, 2012) - broadly, the strategic management of research outputs intended for research audit purposes. As a methodology for professional development, SoTL provides a space for dialogic critique of singular investigations that contribute to advancing individual and collective knowledge of the field of higher education. In a context where approaches to practice have become driven by competitivity and international rankings that rely on objectivist understandings of practice (translated into reductive, easy-to-read metrics) for their judgments, SoTL presents an alternative to "hard-shelled” (Scott, 2009 p. xiii) or "managed" forms of research. Furthermore, whilst managed research tends to clearly dissociate research activities from teaching activities and promote de-contextualised and dis-intellectualized views of teaching, SoTL fully embraces the complexity and the "intellectual nature" - to cite Hutchings et al again — of educational practice at tertiary level. I outline in this paper the benefits of SoTL as a methodology for professional development in the complex intellectual field of higher education teaching.

\section{PROMOTING A DEMOCRATIC AND DIALOGIC FORM OF PROFESSIONAL DEVELOPMENT}

I will start by situating SoTL in the context of teaching in today's universities and colleges. Higher education, in the West especially, takes place in a context of unremitting competition in the race for attracting and retaining students and funding. This competitive ethos pervades most aspects of university life and academic practices. It is being driven, in the UK particularly, by two seemingly paradoxical policy lines: ever-decreasing direct state funding and ever-increasing state-initiated regulation. The state's intention is to get the best possible output from universities from the least possible input_-an instantiation of what Lyotard has called "performativity" (Lyotard, 1984). This approach is sustained by a monitoring of systems and practices through (mainly) quantitative evaluations that compare and rate individuals and institutions. These ratings are interpreted by the public, students, and eventually the sector itself as a proxy for excellence.

I am proposing that SoTL provides a counter-model to this performativity model. It offers a space for critique and endorsement of practice, and for collaboration, which is more powerful to enhance practice than the competitive model that underpins research and teaching activities in higher education presently. I have suggested elsewhere (Fanghanel, 2012) that SoTL, as an approach to academic practice, could inform not just the teaching function but also the research function within universities. As a collaborative transdisciplinary methodology for professional development, SoTL can contribute sig- 
nificantly to enhancing understandings of practice. It can also inflect, as a new paradigm, the discovery-based model of research that dominates the academic field by questioning assumptions about objectivity, uncovering the richness of context-related epistemologies, and challenging expectations regarding methodology or theory (Rege Colet, McAlpine et al., 2011; Fanghanel, 2012). I am inspired in my reflection by the work of Callon et al. (2001) who, focusing specifically on scientific research, seek to promote a "dialogic democracy" space for science research (p. 10). In their model, there is a strong emphasis on the need to combine laboratory-based experiments with collaborative user-led research. I propose that SoTL is a democratic form of inquiry as it enables multiple voices (including academics, students, and student support specialists, for example) to be heard in the public space; it is also a dialogic mode of inquiry because of the dissemination strategies it uses, which are based on discussions and dialogue, where "going public" means more than just publishing in academic journals.

\section{WHY IS SOTL A POWERFUL TOOL FOR PROFESSIONAL DEVELOPMENT IN HIGHER EDUCATION?}

SoTL's richness is not in the model originally devised by Boyer, but in what it has become. There has been much discussion of Boyer's representation of scholarship. Cousin (2008) discerned epistemic bias and the re-introduction of hierarchies within this model, with the scholarship of "discovery" and "integration" being seen as more desirable than that of "application" or "teaching" (p. 92). Elton (2005) thought Boyer's model was not supported by any "convincing rationale" but suggested that the notion of scholarship was close to the Humboldtian notion of "Wissenschaft," which is about learning "in research mode" (p. 108), so somehow condoning the relation to "discovery." Boyer's categories, which he saw as "separate, yet overlapping functions" (Boyer, 1990, p. 16), are in fact quite normative and remain "ideal type" descriptions that may indeed, as suggested by Cousin, not be neutral. In any case, they are not fully recognized by the academic community, nor do they carry equal weight; the scholarship of discovery clearly overpowers all others in the academic "psyche," or in academic structures, at this moment in time.

Considering what the Scholarship of Teaching (as it was originally known) has become, one can state that a significant shift has taken place since the early 1990s in terms of how teaching is being conceptualized-possibly under the influence of constructivist theories of knowledge and campaigns to make explicit the connection between research and teaching. The emphasis has shifted from teaching to teaching and learning with a deliberate intention to bring students into the equation (see Prosser \& Trigwell, 1999) and to focus on teaching as a reciprocal process. In this context, over the past two decades or so, teaching and learning has become a valid field of inquiry in its own right, and SoTL a space where both critique and endorsement of practice can take place. SoTL has produced an interdisciplinary body of knowledge disseminated through retreats, seminars, online discussions, conferences, and publications. I argue that its power as a professional development tool in universities stems from the following characteristics:

- It examines processes that impact on the learning experience rather than seeing teaching as a self-contained context-free action.

- It acts as a device for the transfer of knowledge to specific disciplinary and institutional contexts. 
- It provides spaces for interdisciplinary and cross-institutional reflection.

- It is a scholarly methodology to monitor and evaluate educational innovation.

There exists a range of models to promote the professional development of academics. Mentoring, for instance, is a well-established model to induct newcomers into a community of practice (Blackwell \& McLean, 1996; Cox, 1997; Knight \& Trowler, 1999; Buchanan et al., 2008). In Australia, the UK, and some European countries, more formal inductions into the knowledge base of teaching and learning have been introduced that have resulted in formal academic programmes tailored to the needs of academics. Capitalizing on informal learning has also been suggested as an effective way to develop understandings of practice (Knight, et al., 2006). The main limitations of these models have been examined (e.g., Knight, 2002; Fanghanel, 2004; D’Andrea \& Gosling, 2005; Trowler et al., 2005; Manathunga, 2006; Kandlbinder, 2007; Lee et al., 2010). These limitations relate inter alia to a lack of acknowledgment in mentoring of issues of power, to the assumption that seniority warrants knowledge and insightfulness into teaching and learning, to the lack of attention given to teaching and learning as a collective endeavour, and to the need to promote a formal understanding of practice based on a body of knowledge that has been peer-reviewed and tested.

At the risk of over-simplifying this body of research, I will say that teaching in higher education is an activity that cannot be reduced to a set of principles of good practice, or prescriptive recipes. Because it involves people, processes, and contexts, and because it is mediated through the interplay of agency (how people act in practice) and structures (the curriculum, rules regulating assessment and progress, regulations on attendance and quality), teaching and the management of learning are highly complex activities. I therefore argue that inquiry into practice through SoTL is the only way for academics to understand practice and maintain a sense of manageability in respect to their interactions with students. It also anchors professional development in a non-deficit paradigm (Hutchings et al., 2011) where the focus is on systematic critical examination of an ever-changing object of inquiry. By the same token, it shifts the emphasis of inquiry from a focus on product (number of citations, impact factors, institutional and departmental rankings) to a focus on process (how practice can be changed through inquiry, discussion, and experimentation). This is instantiated in the focus on dissemination that is inherent in SoTL - "going meta" (Hutchings \& Shulman, 1999, p. 12), sharing spaces where analyses of practice are reviewed and debated, thus building the "commons" where resources and knowledge sharing is open to all.

\section{SOTL AS A PROCESS-FOCUSED METHODOLOGY THAT ACKNOWLEDGES THE COMPLEXITY OF PEDAGOGICAL PRACTICE}

I am particularly interested in the process-focused nature of the SoTL inquiry. With its emphasis on methods, reflection, and dialogue rather than on outputs, it has potential as a paradigm-shifting method of inquiry-emphasizing the local, collaborative, and dialogic nature of practice and the transformation of practice through inquiry. As indicated earlier, competitivity has been the driving force behind teaching and research activities in universities for several decades now. In the UK and Australia particularly, where national ratings of research outputs have been operationalized across the sector through a national scheme for research excellence, institutions, departments, and individuals have 
developed strategies to play the research "game" (Lucas, 2006, pp. 93-94). Some (perhaps predictable) consequences of this approach are beginning to emerge as examples of misconduct showing researchers taking short-cuts, fabricating and falsifying findings for the sake of getting published. In contrast, SoTL promotes collaborative dialogic inquiry environments that are suited to today's context and can challenge the dominance of managed research. The aim in SoTL is not to publish but to uncover the complexity of academic practice through reflection and engagement with relevant partners (colleagues, students) and to draw lessons that are subjected to debate and contradiction. Change emerges from inquiry.

\section{SOTL AS A MECHANISM TO FACILITATE CROSS-FERTILIZATION AND TRANSFER TO SPECIFIC CONTEXTS}

Faculty development is a relatively immature field, indeed only embryonic in some parts of the world. Whilst research development is a well-established activity as part of doctoral education programmes, the concept of academic professional development for teaching in higher education is relatively new. It has not been fully exploited in Europe in particular, where the licence to teach, without any specific preparation, a subject in which one is an expert is often taken for granted. The countries and regions that have developed frameworks to support faculty in their roles as teachers generally rely on central development programmes or centralised forms of interventions through student evaluations of their courses. Some attention has been paid to the importance of anchoring faculty development programmes in the disciplines (Manathunga, 2006; Peseta, Manathunga, \& Jones, 2010), but on the whole the education of new faculty tends to rely on pedagogical models that do not problematize transfer of knowledge from one context to another: from a generic context to discipline-specific practice, and from an abstract conceptualization to a specific department where routines and beliefs about teaching and learning may be different. In spite of an important body of research that shows the difficulty of transferring knowledge from one context to another (e.g., Tuomi-Gröhn \& Engeström, 2003; Guile \& Young, 2003), and specifically of transferring knowledge gained on the faculty educational programmes to situated practice (Fanghanel, 2004; Fanghanel, 2007), typically in the UK, it is generally a central programme that introduces academics to the complexities of academic discipline-based practice.

In a study published a few years ago, examining the forms of educational programmes available to new lecturers in the UK within a theoretical paradigm in which the context of practice was seen as critical to change, I identified specific context-related challenges to transfer from central programmes to local practice (Fanghanel, 2004):

- New lecturers have little agency within their own department to operationalise changes in practice.

- Lecturers' ideologies and their beliefs about the purpose of a university education may clash with theories and ideas explored on faculty development programmes.

- Unless the department facilitates a translation of what has been learnt on programmes to practice, transfer is jeopardised by specific policies or ways of working in the academic departments.

- The influence of senior colleagues and mentors within a department is crucial to mediate the interface with central educational development programmes. 
- Discipline conventions and beliefs about the discipline play a significant part in the way new lecturers will teach in practice.

To theorise a little about this challenge of transferring to a different context, I would like to consider the work of researchers who have reflected on transfer by analysing practice within the theoretical framework of "activity systems" (i.e., Guile \& Young, 2003: TuomiGröhn \& Engeström, 2003). For these researchers, transfer is not simply a cognitive activity inherent in the learning process, as cognitivist theorists tend to see it when they envisage learning as residing solely "in the head." Nor do they see it as something that is emerging from inference from the context of practice as do advocates of "situated learning” (e.g., Lave \& Wenger, 1991; Brown, Collins, \& Duguid, 1989). Lave and Wenger, for example, see transfer as the ability to identify the affordances of practice to deploy what has been learnt in another context, but they do not give any indications about how this happens. Engeström and the activity theorists cited above, on the other hand, propose that the facilitation of transfer to a new context must be deliberately embedded in the learning event. They suggest that the pedagogical approach of a teacher must therefore include what they call "expansive learning," defined as "when some individuals involved in a collective activity take the action of questioning the existing practice" (Tuomi-Gröhn \& Engeström, 2003, p. 30).

So expansive learning envisages individual learning in the context of practice as occurring through collective reflection and development. The emphasis is on "common/ shared activity," the analysis of "developing systems," and "recruiting a growing number of participants in the transformation effort” (Tuomi-Gröhn \& Engeström, 2003, p. 3031 ). They therefore suggest that a critical dialogic approach is needed to make practice progress through expansive learning. They propose that transfer through expansive learning is facilitated by the following:

- Questioning received wisdom

- Analysis

- Modelling - construction of a model that is not initially known to the instructor

- Examining the model

- Implementing solutions/ideas and new models of practice

- Consolidating practice and proliferating

- Evaluating

(Adapted from Tuomi-Gröhn \& Engeström, 2003, p. 31)

SoTL work is a process in which this kind of reflective methodology is used: questions are asked about existing practices; analysis (and hypotheses) are applied; and new models are devised, implemented, and tested, reinforcing and transforming existing practices. At its best, SoTL also allows for the learning from practice to feed back into theoretical conceptualization of teaching and learning. Given the crucial role of the context of practice when one seeks to understand teaching and learning, and the significant impact of the meso level of practice (the department) in enabling or preventing change, SoTL — as a space of encounter between theory and practice-is a potent locus. Its potential as a methodology for enhancing practice is greater than that of methodologies that do not clearly articulate a theory of change - whether they assume unproblematic transmission 
of educational 'wisdom' (as in mentorship programmes) or transmission of an educational knowledge base (as in the case of the programmes accredited in UK universities for example) or whether they rest on theoretical models that privilege informal learning (Eraut, 2000; Knight, Tait et al., 2006). For the sake of my argument, and to sum-up this section, I propose that the transfer of pedagogical principles to specific disciplines is as challenging as the transfer of abstract knowledge to new situations or new contexts of which Tuomi-Gröhn and Engeström talk, and I see SoTL as a vehicle for linking these intellectual and practical dimensions of teaching. To use Guile and Young's (2003) terminology, SoTL supports "boundary-crossing" (p. 79).

It is also very important in my view that this process happens in heterogeneous groups. Academics are not all coming from the same communities and horizons, and heterogeneity enables progress. SoTL is a community of practice engaged in testing and critiquing pedagogical principles across disciplines. The richness gained from exchanges with other disciplines and other contexts cannot be under-estimated; the potential impact for institutional enhancement is significant (Hutchings, Huber et al., 2011). Hutchings (2007) and Hutchings and Huber (2008) have identified SoTL's theoretical richness and shown that academics resort in particular to semiotics, reader-response theory, hermeneutics, error and misconceptions (linguistics, language), and resilience theories to examine their pedagogical practice. They conclude that SoTL "does not come from a single body of work or field, nor does it travel in a straight line" (Hutchings \& Huber, 2008, p. 232). There is increasing variety and richness in the theories used in SoTL and therefore scope for these theoretical inputs to be travelling across disciplines. Huber and Hutchings talk of SoTL as a "big tent" that accommodates different theoretical viewpoints (2005, p. 30). SoTL is also a "trading zone" (Huber \& Morreale, 2002, p. 73), a space where goods are being exchanged (ideas, methods, references) and collaborations are being formed. The emphasis on learning from other disciplines, becoming able to understand varied theoretical or ideological positions, in other words learning from that which is different, seems to me one the great assets that SoTL yields. Learning to see from a different perspective is possibly one of the most important attributes for both academics and students to effectively study and work in today's world.

\section{SOTL AS A METHODOLOGY TO MONITOR AND EVALUATE EDUCATIONAL INNOVATION}

Finally, at the institutional level, I propose that SoTL is a vehicle suited to monitor and evaluate innovation. Innovation in teaching and learning is not necessarily radical. It is probably best managed through incremental, small-scale, reflective steps that involve students and teaching teams, through reflection on "real" effects, rather than on "espoused" effects, and through cycles of feedback (Argyris, 1977). SoTL supports this process as an approach that allows for the scaffolding of innovation in the curriculum through cycles of reflection and experimentation. Outcomes of the inquiry feed back into practice and inform the next cycle of inquiry. SoTL thus informs academics about the degree of success of an intervention or about students' perceptions of a novel strategy. This approach is relatively risk-free, as it generates change that is monitored at local level through iterations of inquiry over the long term.

Thus, practice informed by SoTL (often applied to innovative endeavours) is selfmonitored through inquiry. The examples of such self-constructed innovation listed below 
have emerged from a quick browsing of the papers presented at the London SoTL International Conference between 2004 and 2010. It is not a comprehensive collection of examples of innovations that have been subjected to inquiry, but it serves to illustrate the way in which SoTL warrants purchase on innovation through testing effects and impact on students. The areas of innovation included the following:

\section{Assessment}

Self-assessment

Formative assessment

Portfolio assessment

Innovative ways of combating plagiarism

Ipsative assessment (assessment which is based on a comparison with a learner's previous performance rather than external standards)

\section{Learning}

Learning logs to develop meta-cognitive skills

Mind-mapping to promote understanding

Thinking experiments

Enhancing writing/key skills

Online writing to develop critical thinking

Motivation strategies

Scientific writing to enhance the link between teaching and research

Problem-based learning to facilitate the development of clinical reasoning skills

Motivational interviewing

Undergraduate publishing

Intercultural learning

Use of technology

Newsroom classroom model for media students

Using media to develop inspirational learning

Audio feedback and electronic feedback to combat plagiarism

Online discussions to promote learning

Mobile tutoring

Web 2.0

Simulations

Multi-media/video to develop students' perceptions of learning

Other forms of technology-enhance learning

\section{Practice/industry interface}

Developing ethical awareness

Involving employers in the curriculum

Doctor role modelling

Faculty development

Interdisciplinary teaching

Interdisciplinary collaborative pedagogy 
Interdisciplinary curriculum

Interdisciplinary research (English and Maths; Law and Music)

Developing undergraduate research

Patterns of participations in small group teaching

This list shows, as Hutchings et al (2011, p. 9), suggest, that SoTL contains "multitudes"the big tent paradigm. I propose that SoTL practice is particularly suited to supporting innovation in higher education as it enables faculty to work collaboratively, and learn from each other as they discover new ways of engaging with student learning. They can thus walk away from the "pedagogical solitude" (Hutchings, et al., 2011, p. 125) they may experience as innovators in university departments.

\section{CONCLUSION}

Whilst there has been criticism levelled at the SoTL community in terms of the quality and usefulness of its outputs and of the varying degree of theorisation in its work, those debates have only served to reinforce the paradigms associated with managed research and have deflected from the real strengths of the SoTL approach in developing practice through criticality, direct experience, and reliance on theoretical/abstract knowledge. Rather than being a "show and tell" act, the SoTL approach provides a reflective methodology for the professional development of academics. It is therefore not a lower form of educational research but a sophisticated and strategic form of professional development that focuses on processes, working across boundaries, and making public its findings. It is a model of inquiry that is altruistic - the emphasis is on getting to know better so that students benefit from that knowledge - and democratic as it engages multiple voices in the public space.

I will conclude on the challenges ahead. The main challenge for SoTL is not in the approach itself but rather in how the SoTL community is able to communicate better understandings of what it can do. The opposition with "proper educational research" is just not sufficient; the question of "rigor" is epistemologically an irrelevance if one seeks to develop more singular methodologies to develop richer conceptualizations of practice (Cousin, 2008, pp. 96-97). A second challenge is to promote the value of this form of inquiry so that it can become a form of mainstream professional development without losing its altruistic and democratic components. The third challenge is to better understand and manage the interface with the department and the discipline where ultimately the practice is located. Finally, I believe there is also scope for SoTL to develop a stronger political (in the original Greek sense) voice in the HE landscape to shape practices and curricula in universities that can respond to the challenges of educating students to live and work in a globalised world. SoTL has a strong role to play in developing pedagogies that provide a safe space for contestation, collaboration, and dialogue and are underpinned by the complex theories of knowledge that are appropriate to meet the challenges of living in today's complex world. It also has a strong role to play in ensuring that the values I have defended here (collaboration, democracy, dialogue, altruism) do not get lost as governments focus on the economic and revenue dimensions of higher education.

Joëlle Fanghanel is Professor of Higher Education and Director of the Institute for Teaching, Innovation and Learning at the University of West London, United Kingdom. 


\section{REFERENCES}

Argyris, C. (1977) Double loop learning in organizations. Harvard Business Review 55 (5): $115-125$.

Blackwell, R. and McLean, M. (1996) Mentoring new university teachers. International Journal for Academic Development 1 (2): 80-85.

Boyer, E. (1990) Scholarship Reconsidered: Priorities of the Professoriate. Princeton, New Jersey: Carnegie Foundation for the Advancement of Teaching.

Brew, A. (2007) Approaches to the scholarship of teaching and learning. In A. Brew and J. Sachs (Eds.), Transforming a University: The Scholarship of Teaching and Learning in Practice. Sydney: Sydney University Press: 1-10.

Brew, A. (2011) Higher Education Research and the Scholarship of Teaching and Learning: The Pursuit of Excellence. International Journal for the Scholarship of Teaching and Learning 5 (2): http://www.georgiasouthern.edu/ijSoTL.

Brown, J. S., Collins, A. and Duguid, P. (1989) Situated Cognition and the Culture of Learning. Educational Researcher 18: 32 - 42.

Buchanan, J., Gordon, S. et al. (2008) From mentoring to monitoring: the impact of changing work environments on academics in Australian universities. Journal of Further and Higher Education 32 (3): 241-250.

Callon, M., Lascoumes, P. and Barthe, Y. (2001) Acting in an Uncertain World: An Essay on Technical Democracy. Cambridge, Massachusetts and London, England: The MIT Press.

Cousin, G. (2008) Reconsidering scholarship reconsidered. In R. Murray. The Scholarship of Teaching and Learning in Higher Education. Maidenhead: McGraw-Hill The Society for Research into Higher Education and Open University Press: 91-97.

Cox, M. D. (1997) Long-term patterns in a mentoring program for junior faculty: Recommendations for practice. To Improve the Academy 16: 225 - 268.

D'Andrea, V. and Gosling, D. (2005) Improving Teaching and Learning in Higher Education: A whole institution approach. Maidenhead: The Society for Research in Higher Education and Open University Press.

Elton, L. (2005) Scholarship and the Reseach and Teaching Nexus. In R. Barnett. Reshaping the University: New Relationships between Research, Scholarship and Teaching Maidenhead: The Society for Research in Higher Education and Open University Press: 108-118.

Eraut, M. (2000) Non-formal learning, implicit learning and tacit knowledge in professional work. In F. Coffield. The necessity for informal learning. Bristol: The Policy Press: 12 - 31.

Fanghanel, J. (2004) Capturing dissonance in university teacher education environments. Studies in Higher Education 29 (5): 575 - 590.

Fanghanel, J. (2007) Local responses to institutional change: a discursive approach to positioning. Studies in Higher Education 32 (2): 187-205.

Fanghanel, J. (2008) The Shaping of SoTL in the UK: Reflections on the London SoTL International Conference. ISSOTL Newsletter 3 (1): 9 -10.

Fanghanel, J. (2012) Being an Academic. London and New York: Routledge. 
Guile, D. and Young, M. F. D. (2003) Transfer and Transition in Vocational Education: Some Theoretical Considerations. In T. Tuomi-Gröhn and Y. Engeström Between School and Work: New Perspectives on Transfer and Boundary-Crossing. Amsterdam: Pergamon: 63-81.

Huber, M. T. and Hutchings, P. (2005) The Advancement of Learning: Building the Teaching Commons. San Francisco: Jossey-Bass.

Huber, M. T. and Morreale, S. P., Eds. (2002) Disciplinary styles in the scholarship of teaching and learning: Exploring common ground. Washington, D.C.: American Association for Higher Education.

Hutchings, P. (2000) Opening Lines: Approaches to the Scholarship of Teaching and Learning. Palo Alto, CA: The Carnegie Foundation for the Advancement of Teaching.

Hutchings, P. (2007) Theory: The Elephant in the Scholarship of Teaching and Learning Room. International Journal for the Scholarship of Teaching and Learning 1 (1): http://academics .georgiasouthern.edu/ijSoTL/v1n1/essays/hutchings/I_Hutchings.pdf

Hutchings, P. and Huber, M. T (2008) Placing Theory in the Scholarship of Teaching and Learning. Arts and Humanities in Higher Education 7 (3): 229-244.

Hutchings, P., Huber, M. T., and Ciccone, A.. (2011) Scholarship of Teaching and Learning Reconsidered: Institutional Integration and Impact. San Francisco: Jossey-Bass.

Hutchings, P. and Shulman, L. S. (1999). The Scholarship of Teaching: New Elaborations, New Developments. Change 31 (5): 10-15.

Kandlbinder, P. (2007) The Challenge of Deliberation for Academic Development. International Journal for Academic Development 12 (1): 55-59.

Knight, P. (2002) Being a Teacher in Higher Education. Buckingham: The Society for Research into Higher Education and Open University Press.

Knight, P., Tait, J. et al. (2006) The professional learning of teachers in higher education. Studies in Higher Education 31 (3): 319-339.

Knight, P. and Trowler, P. (1999) It takes a village to raise a child: mentoring and the socialisation of new entrants to the academic professions. Journal of Mentoring and Tutoring $7(1): 23-34$.

Kreber, C. (2013) Authenticity in and through teaching in higher education: The transformative potential of the scholarship of teaching. London and New York: Routledge.

Lave, J and Wenger, E (1991) Situated Learning: Legitimate Peripheral Participation, Cambridge. Cambridge University Press.

Lee, A., Manathunga, C. et al. (2010) Shaping a culture: oral histories of academic development in Australian universities. Higher Education Research and Development 29 (3): 307-318.

Lucas, L. (2006) The Research Game in Academic Life. Maidenhead: The Society for Research into Higher Education and Open University Press.

Lyotard, J. F. (1984) The Postmodern Condition. Manchester: Manchester University Press.

Manathunga, C. (2006) Doing Educational Development Ambivalently: Applying postcolonial metaphors to educational development? International Journal for Academic Development 11(1): 19-29. 
McNay, I. (2009) Research quality assessment: objectives, approaches, responses and consequences. In A. Brew and L. Lucas. Academic research and researchers. Maidenhead: McGraw Hill, The Society for Research into Higher Education and Open University Press: 35-53.

Parker, J. (2002) A New Disciplinarity: communities of knowledge, learning and practice. Teaching in Higher Education 7(4): 373-386.

Peseta, T., Manathunga, C., et al. (2010) What kind of interdisciplinary space is academic development? In M. Davies, M. Devlin and M. Tight Interdisciplinary higher education: international perspectives on higher education research Vol 5. Amsterdam: Emerald Group Publishing Ltd: 97-111.

Prosser, M. \& Trigwell, K. (1999) Understanding Learning and Teaching: The Experience in Higher Education. Buckingham: Society for Research into Higher Education and Open University Press.

Prosser, M. and Trigwell, K. (2009) ISSOTL 2008 Conference More Scholarly. ISSOTL Newsletter: The International Commons 4, 1.

Rege Colet, N., McAlpine, L., et al. (2011) Le concept de Scholarship of Teaching and Learning: La recherche sur l'enseignement supérieur et la formalisation des pratiques enseignantes. Revue Recherche et Formation 67: 91-104.

Scott, P. (2009) Foreword. In Brew, A. and Lucas, L. (Eds.) Academic Research and Researchers. Maidenhead: Society for Research into Higher Education and Open University Press.

Trowler, P., Fanghanel, J. et al. (2005) Freeing the Chi of Change: The Higher Education Academy and Enhancing Teaching and Learning in Higher Education. Studies in Higher Education 30 (4): 427-444.

Tuomi-Gröhn, T. and Engeström, Y. (2003) Conceptualizing Transfer: From Standard Notions to Developmental Perspectives. In T. Tuomi-Gröhn and Y. Engeström. Between School and Work: New Perspectives on Transfer and Boundary-Crossing. Amsterdam: Pergamon: 19-38. 